\title{
A rare case of thyroid storm
}

\author{
Brock McMillen, Manvinder Shelley Dhillon, Sabrina Yong-Yow
}

Department of Family Medicine, Indiana University School of Medicine, Indianapolis, Indiana, USA

\section{Correspondence to Dr Brock McMillen, bmcmille@|UHealth.org}

Accepted 5 April 2016
CrossMark

To cite: McMillen $B$ Dhillon MS, Yong-Yow $S$. BMJ Case Rep Published online: [please include Day Month Year] doi:10.1136/ bcr-2016-214603

\section{SUMMARY}

Thyroid storm is a rare and life-threatening state of thyroid hormone excess. Rapid recognition of thyroid storm is key to decreasing the morbidity and mortality of this condition. Clinical manifestations of thyroid storm include unexplained weight loss, hyperactivity and irritability. The most common causes of thyrotoxicosis are Graves' disease, toxic multinodular goitre and toxic adenoma. We present a rare case of thyroid storm induced by dual nivolumab and ipilimumab immunotherapy in a patient receiving treatment for advanced melanoma. In this case, our patient was admitted for thyroid storm 1 month after initiating treatment with nivolumab and ipilimumab immunotherapy. The patient was treated with $\beta$-blockers, antithyroid medications and systemic steroids resulting in an improvement in thyroid function testing and symptoms.

\section{BACKGROUND}

Novel immunotherapy agents, nivolumab and ipilimumab, have the capacity to effectively destroy immunogenic tumours such as melanoma through the use of immune checkpoints. ${ }^{1-3}$ Immune-checkpoint inhibitor therapies are evolving to be the mainstay of therapy in BRAF-mutated advanced melanoma. ${ }^{4}$ Ipilimumab is a monoclonal antibody against CTLA-4, boosting T-cell activation and proliferation. ${ }^{5}$ Nivolumab is a human programmed death receptor-1 (PD-1) blocking antibody, which also creates a negative regulatory T-cell response. ${ }^{6}$ Through the use of alternative checkpoints, these agents provide distinct clinical activity in treatment of advanced melanoma compared with monotherapy, as highlighted by Wolchock et $a l .^{4}$ Owing to T-cell activation throughout the body, these agents can cause various autoimmune adverse reactions including immune-mediated pneumonitis, immunemediated colitis, immune-mediated hepatitis, immune-mediated hyperthyroidism and immunemediated hypothyroidism. ${ }^{5}{ }^{6}$ In nivolumab and ipilimumab drug trials, hyperthyroidism occurred in $8 \%(34 / 407)$ of patients. ${ }^{5}$ Four of these patients had grade 3 hyperthyroidism and the rest of the patients had grade 1 or grade 2 hyperthyroidism. ${ }^{5} 6$ We present a rare case of thyroid storm in a patient with advanced melanoma receiving dual nivolumab and ipilimumab therapy.

\section{CASE PRESENTATION}

A 24-year-old Caucasian woman with a history of metastatic melanoma presented to the emergency department, with a 3-day history of intractable nausea, vomiting and anxiety.
She had been initiated on dual nivolumab and ipilimumab therapy 1 month prior and received two courses of therapy thus far. Her last dose was 1 week prior to presentation. She had previously completed 1 year of high-dose interferon therapy. Surgical history included right video-assisted thoracoscopic surgery with right lower lobe wedge resection due to metastasis 6 weeks prior and right cheek melanoma resection 2 years prior. Medical history included depression and anxiety. The patient's medications included atenolol, citalopram and alprazolam. She denied alcohol or illicit drug use. On presentation, she was febrile to $40.3^{\circ} \mathrm{C}$ (104.5 Fahrenheit), tachycardic to $146 \mathrm{bpm}$, and agitated with symptoms of nausea and vomiting. Her blood pressure was stable at $138 / 87$. Her Glasgow coma scale was 15 . On examination, the patient was agitated and acutely anxious but still awake, alert and oriented. She was diaphoretic and flushed with no jugular venous distention, no peripheral oedema, and with regular rate and rhythm on cardiac examination, and clear breath sounds on lung examination. The rest of the physical examination was unremarkable. Most notably, neither thyromegaly, nor exophthalmos, nor tender thyroid was appreciable on physical examination. On the Burch et al diagnostic point scale for thyroid storm, our patient scored 85 . By this scoring system, a score higher than 45 is suggestive of thyroid storm. ${ }^{1}$ The patient was admitted to the intensive care unit (ICU), with endocrinology and oncology consultation.

\section{INVESTIGATIONS}

Initial complete blood count, basic metabolic panel, lipase and urinalysis were all normal. Urine pregnancy test was negative. Blood cultures were obtained and negative at $48 \mathrm{~h}$. An ECG showed sinus tachycardia. The patient's thyroid function tests on the day of presentation were: thyroid stimulating hormone $0.062 \mu \mathrm{U} / \mathrm{mL}$, free thyroxine $4.0 \mathrm{ng} / \mathrm{dL}$ and free triiodothyronine $6.4 \mathrm{ng} / \mathrm{dL}$ (normal range $1.5-3.5 \mathrm{ng} / \mathrm{dL}$ ). Her historical thyroid function tests after receiving interferon therapy but prior to initiation of treatment with nivolumab and ipilimumab were: thyroid stimulating hormone $3.289 \mu \mathrm{U} / \mathrm{mL}$ and free thyroxine $0.7 \mathrm{ng} / \mathrm{dL}$. Thyroid peroxidase and thyroid stimulating immunoglobulin levels were within normal range.

A thyroid ultrasound revealed diffuse thyroid heterogeneity consistent with non-specific thyroiditis. Radioactive iodine uptake study was not performed due to the patient having had a recent CT scan with intravenous contrast. Chest X-ray (CXR) was negative. 
The patient improved symptomatically from her initial presentation and was discharged home the next day from the intensive care unit (ICU).

The patient returned to the emergency department within $24 \mathrm{~h}$ of initial discharge with re-emergence of her symptoms including nausea, vomiting, agitation and anxiety. She was febrile to $38.9^{\circ} \mathrm{C}\left(102^{\circ}\right.$ Fahrenheit) with tachycardia to 120 . All other vital signs were stable. Physical examination remained non-focal. A chest X-ray, urinalysis, basic metabolic panel and complete blood count with differential were unremarkable. Repeat thyroid stimulating hormone was $0.043 \mu \mathrm{U} / \mathrm{mL}$. Free thyroxine improved to $2.1 \mathrm{ng} / \mathrm{dL}$. On the Burch et al diagnostic point scale for thyroid storm, our patient scored 65 .

The patient was admitted to the progressive care unit for concerns of unresolved thyroid storm, with endocrinology and oncology consultation. Investigations were broadened to include a thorough infectious work up that included lactate within normal limits, a negative respiratory viral panel, a negative rapid streptococcus, negative urine gonorrhoea and negative chlamydia PCR. Lumbar puncture was performed and resultant Gram stain, culture, cell count, protein and glucose were all normal. Infectious disease was consulted. Cryptococcal antigen, Clostridium difficile assay, cytomegalovirus antigen, histoplasma antigen, HIV and mono heterophile antibody all resulted negative. Final blood and urine culture results were negative. Repeat blood cultures were negative at $48 \mathrm{~h}$. Urine culture was negative. CT of the chest with intravenous contrast revealed no acute process, most notably no pulmonary embolism.

\section{DIFFERENTIAL DIAGNOSIS}

The patient had signs and symptoms of thyroid storm based on the diagnostic criteria for thyroid storm developed by Burch et al, including agitation, nausea with vomiting, tachycardia, fever and a known history precipitant of ipilimumab and nivolumab treatment. ${ }^{1}$ The differential diagnoses were broad on initial presentation. They included medication-induced thyroid storm, Graves' disease, thyroiditis, thyroid adenoma, toxic multinodular goitre and Hashimoto's thyroiditis. Interferon-induced thyroid dysfunction was less likely given normal thyroid function tests after completion of therapy. Graves' disease was less likely as thyroid-stimulating immunoglobulins were within normal range and the patient was without exophthalmos. Hashimoto's thyroiditis was less likely as thyroid peroxidase immunoglobulins were within normal range. Thyroid ultrasound with Doppler showed neither adenoma nor goitre (figure 1). Therefore, the most likely diagnosis was immune-mediated thyroiditis with resultant thyrotoxicosis with precipitation of thyroid storm. This was

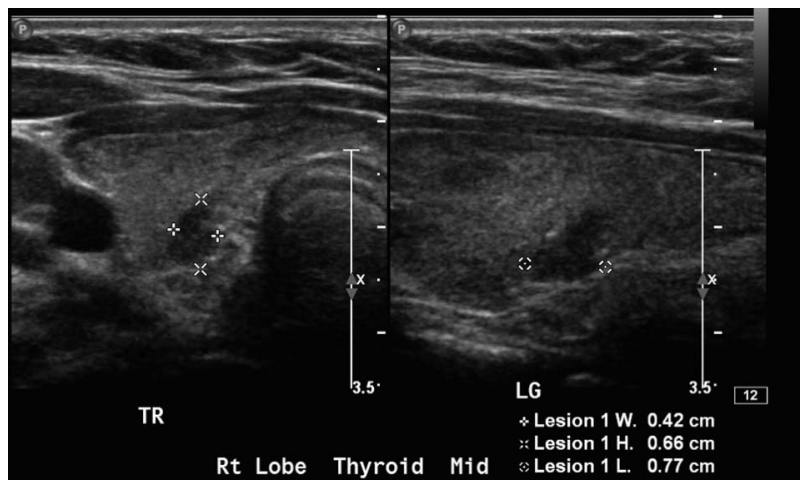

Figure 1 Thyroid ultrasound (US) of our patient during her second admission over the right thyroid lobe showing diffuse thyroid heterogeneity consistent with non-specific thyroiditis.

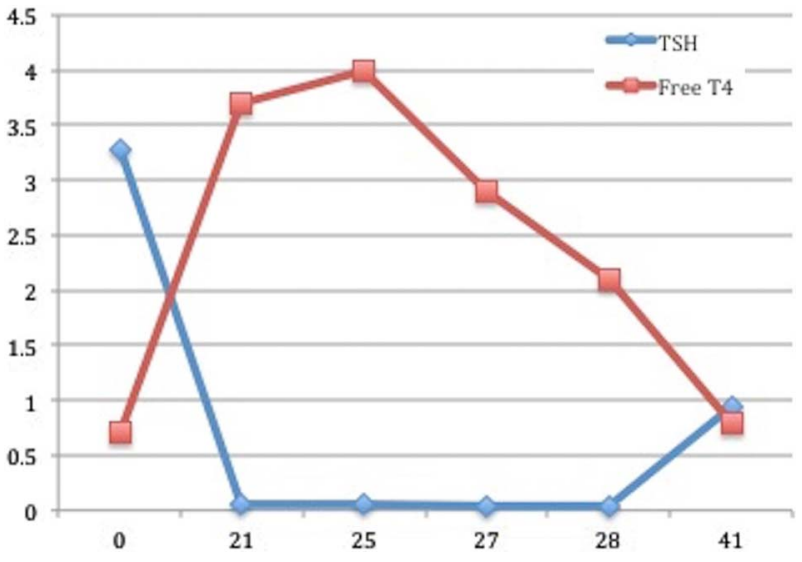

Figure 2 Thyroid function tests obtained over time during our patient's treatment course. Day 0 represents baseline thyroid function tests prior to initial cycle of immunotherapy. Day 21 represents thyroid function tests on day of second cycle. Day 25 represents day of initial presentation of first hospitalisation. Day 28 represents day of presentation of her second hospitalisation.

additionally supported after the trend of thyroid function tests before and after the initiation of nivolumab and ipilimumab immunotherapy was examined (figure 2).

\section{TREATMENT}

The patient, on initial admission to the ICU for thyroid storm, was initiated on propranolol $60 \mathrm{mg}$ every $6 \mathrm{~h}$ to achieve adequate control of her heart rate, and hydrocortisone $100 \mathrm{mg}$ every $8 \mathrm{~h}$. This is slightly under the recommended steroid dose of $1 \mathrm{mg} / \mathrm{kg}$ of prednisone, or equivalent, daily, as suggested by the risk evaluation and mitigation strategy (REMS) for treatment of an immune-mediated adverse reaction induced by ipilimumab. ${ }^{7}$ The patient was also started on methimazole $20 \mathrm{mg}$ every $8 \mathrm{~h}$ based on the drug manufacture's dosing recommendations. On day 2, the methimazole was discontinued as the patient's white cell count trended downwards raising concern for agranulocytosis. She was then started on cholestyramine to help bind and excrete excess thyroid hormone. She was discharged from the ICU on a medication regimen including cholestyramine $4 \mathrm{~g}$ three time a day, hydrocortisone $25 \mathrm{mg}$ two times a day and propranolol $60 \mathrm{mg}$ every $6 \mathrm{~h}$. Minimal steroid dosing on discharge was recommended based on the concern that an elevated steroid dosing would counteract the immunotherapy.

On her second admission, the patient was continued on hydrocortisone $25 \mathrm{mg}$ two times a day. She was started on empiric antibiotics including vancomycin and meropenem after $48 \mathrm{~h}$ of unresolved fever and intermittent tachycardia. Antibiotics were discontinued after $24 \mathrm{~h}$ of the patient becoming afebrile and after negative infectious work up. She was transitioned to oral prednisone $80 \mathrm{mg}$ daily at the time of discharge.

\section{OUTCOME AND FOLLOW-UP}

Five weeks after discharge, the patient's thyroid function tests improved: thyroid stimulating hormone was $0.951 \mu \mathrm{U} / \mathrm{mL}$ and free thyroxine was $0.8 \mathrm{ng} / \mathrm{dL}$. She was euthyroid and only reporting of fatigue. She remained on high-dose prednisone therapy with plans to taper the dose.

\section{DISCUSSION}

This case report is an example of dual nivolumab and ipilimumab immunotherapy causing an immune-mediated 


\section{Learning points}

- Nivolumab and ipilimumab therapy shows great promise in improving the prognosis for patients with advanced melanoma, but providers should be mindful that this therapy may be linked to immune-related adverse events such as thyrotoxicosis and thyroid storm.

- Thyroid function tests and thyroid symptoms should be monitored in patients with metastatic melanoma undergoing nivolumab and ipilimumab immunotherapy.

- Prompt recognition of thyroid storm is potentially life-saving. However, the clinical diagnosis is challenging given the non-specific signs and symptoms. Tools such as the Burch et al point scale for the diagnosis of thyroid storm can be helpful as it attributes points for thermoregulatory dysfunction, central nervous system effects, gastrointestinal-hepatic dysfunction, cardiovascular dysfunction and precipitant history. Scores are totalled and a score of 45 or greater is highly suggestive of thyroid storm. ${ }^{1}$

- Prompt treatment of thyroid storm is potentially life-saving. Close monitoring in an inpatient setting in addition to treatment with $\beta$-blockers, antithyroid agents, steroids and bile sequestering therapies are recommended. Endocrinology consultation is also beneficial.

- Thyroid storm induced by dual nivolumab and ipilimumab treatment may require high-dose steroid therapy based on the existing recommendations to treat immune-mediated adverse reactions with $1 \mathrm{mg} / \mathrm{kg}$ of prednisone or equivalent. ${ }^{7}$ However, it is unclear if this is too high of a dose in the setting of its potential interaction with the immunotherapy.

thyrotoxicosis, precipitating thyroid storm. Thyroid storm is a clinical diagnosis, but the point scale system developed by Burch et al can aid in confirming the diagnosis. This scale system assigns points in the categories of thermoregulatory dysfunction, central nervous system effects, gastrointestinal-hepatic dysfunction, cardiovascular dysfunction and precipitant history. Scores are totalled and a score of 45 or greater is highly suggestive of thyroid storm. ${ }^{1}$ Our patient's score totalled 85 on initial presentation and 65 on readmission.

It is important to point out that our patient was treated with interferon for 1 year prior to the initiation of nivolumab and ipilimumab. Interferon has also been implicated in causing thyroid dysfunction. However, our patient had thyroid function testing that was within normal range prior to the initiation of nivolumab and ipilimumab.

A database search for 'nivolumab and ipilimumab thyrotoxicosis' revealed one case report where ipilimumab alone caused thyroid storm in a patient receiving immunotherapy for melanoma. In that case, antithyroid medications were started with resolution of symptoms. Steroids were considered, but not started because of oncologic concern for reversal effects of the patient's immunotherapy. ${ }^{8}$

Individual clinical drug trials of nivolumab and ipilimumab do not mention any cases of thyroid storm. Prescribing information does recommend monitoring thyroid function tests prior to and periodically during the course of treatment and medically managing adverse outcomes. There is currently no dose adjustment in the event of thyroid dysfunction and no dose recommendation for corticosteroid administration in the event of an adverse reaction. ${ }^{5}{ }^{6}$ The recommended steroid dose of $1 \mathrm{mg} / \mathrm{kg}$ of prednisone, or equivalent, daily, is suggested by the REMS for treatment of an immune-mediated adverse reaction induced by ipilimumab. ${ }^{7}$

In conclusion, we present a rare case of nivolumab-induced and ipilimumab-induced thyroid storm.

Prompt recognition of thyroid storm and initiation of highdose steroids in our patient was important in preventing possible morbidity and mortality. Early tapering of steroid therapy due to concern about steroids counteracting immunotherapy in the setting of life-threatening malignant melanoma was potentially responsible for the incomplete resolution of the thyroid storm seen on readmission. Our patient improved after re-initiation of high-dose steroid therapy with a slow taper. However, long-term outcomes are still questionable at this point given her adverse response to these novel agents.

Competing interests None declared.

Patient consent Obtained.

Provenance and peer review Not commissioned; externally peer reviewed.

\section{REFERENCES}

1 Bahn RS, Burch HB, Cooper DS, et al. Hyperthyroidism and other causes of thyrotoxicosis: management guidelines of the American thyroid association and American association of clinical endocrinologists. Endocr Pract 2011;17:456-520 [cited 10 Mar 2016).

2 Jameson JL, Mandel SJ, Weetman AP. Disorders of the thyroid gland. In: Harrison's principles of internal medicine. 19th edn. New York, NY: McGraw-Hill, 2015. Retrieved 4 January 2016. http://accessmedicine.mhmedical.com.proxy.medlib.uits. edu/content. aspx?bookid $=1130$ \&Sectionid $=7951787$

3 Kim KB, Davies MA, Rapini RP, et al. The MD Anderson manual of medical oncology. New York, NY: McGraw-Hill, 2011. Retrieved 24 August 2015. http:// accessmedicine.mhmedical.com. proxy.medlib.uits.iu.edu/content.aspx? sectionid=39902069\&bookid=379\&jumpsectionID=39908292\&Resultclick=2

4 Wolchock JD, Kluger H, Callahan MK, et al. Nivolumab plus ipilimumab in advanced melanoma. N Engl J Med 2013;369:122-33 (cited 10 Mar 2016).

5 Yervoy® (Ipilimumab) [Internet] 2011 [updated Oct 2015; cited Mar 2016]. http:// packageinserts.bms.com/pi/pi_yervoy.pdf

6 OPDIVO® (Nivoloumab) [Internet] 2014 [updated Jan 2016; cited Mar 2016]. http:// packageinserts.bms.com/pi/pi_opdivo.pdf

7 YERVOY (ipilimumab) US Prescribing Information: Risk Evaluation and Mitigation Strategy (REMS). 2011 (updated Feb 2012; cited Mar 2016). http://www.accessdata. fda.gov/drugsatfda_docs/rems/Yervoy_2012-02-16_Full.pdf

8 Yu C, Chopra IJ, Ha E. Endocrinology, Diabetes \& Metabolism Case Reports. 2015:140092 (cited 16 Mar 2016). http://doi.org/10.1530/EDM-14-0092 
Copyright 2016 BMJ Publishing Group. All rights reserved. For permission to reuse any of this content visit http://group.bmj.com/group/rights-licensing/permissions.

BMJ Case Report Fellows may re-use this article for personal use and teaching without any further permission.

Become a Fellow of BMJ Case Reports today and you can:

- Submit as many cases as you like

- Enjoy fast sympathetic peer review and rapid publication of accepted articles

- Access all the published articles

- Re-use any of the published material for personal use and teaching without further permission

For information on Institutional Fellowships contact consortiasales@bmjgroup.com

Visit casereports.bmj.com for more articles like this and to become a Fellow 